\title{
DYNAMIC VISUALIZATION OF SENSOR MEASUREMENTS: CONTEXT BASED APPROACH
}

\author{
Radim Stampach, Petr KubiceK, Lukas Herman \\ Laboratory on Geoinformatics and Cartography, Masaryk University, Brno, Czech Republic
}

Manuscript received: July 7, 2014

Revised version: July 24, 2015

\begin{abstract}
Stampach R., Kubicek P.,Herman L., 2015. Dynamic visualization of sensor measurements: Context based approach. Quaestiones Geographicae 34(3), Bogucki Wydawnictwo Naukowe, Poznań, pp. 117-128, 7 figs. DOI 10.1515/quageo-2015-0020, ISSN 0137-477X

ABSTRACT: An amount of data measured with sensors is increasing year to year. Every sensor has a location and sensor data are mostly measured for long time period, so visualization of location and regular updating of visualized value is necessary. Various characteristics (e.g. meteorological conditions) can be automatically read at frequent intervals and those readings can be aggregated into the interactive map visualization. This map must be not only legible but also understandable also for readers that are experts in their specialisation, however, not in cartography. This paper presents possibilities of using and implementation of adaptive cartography and visual seeking principles for interactive visualization and analysis of sensor based data measured in real time. Our solution is described on experimental application for precise farming that we developed during research project Agrisensor.
\end{abstract}

KEYWORDS: adaptive cartography, visual seeking, interactive map, sensor data, precise farming

Address of the corresponding author: Radim Stampach, Department of Geography, Faculty of Science, Masaryk University, Brno, Czech Republic; e-mail: stampach@mail.muni.cz

\section{Introduction}

GIS and cartographic visualization play important roles in many areas of life and can be used to wide spectra of purposes. It is possible to mention many various examples. Stanek et al. (2010) or Grönlund (2005) describe cartographic visualization for operators in operational centres of emergency system. Stampach, Geryk (2011) or Beroll et al. (2007) describe using of spatial data, GIS and maps for analysis of public health system and health status of population. Geryk et al. (2010 and 2013) use maps to describe situation of various oncological diagnoses in the Czech Republic.

Cartography and maps can be used for the monitoring, prediction and analysis of a situation in space as well as in time (cited Stampach, Geryk 2012: 78). This can be applied both for paper and elec- tronic maps. However, electronic maps have also one another advantage - they can be interactive and they can visualize data in near real time. All mentioned points are very useful for visualizing data from sensors. Visualization of data that are collected by sensors falls between areas that are examined in the context of geovisualization. These research tasks describe in more detail MacEachren, Kraak (2001).

Sensor data are mostly measured automatically for long time period, so visualization of changes in time and regular updating of visualized value is necessary. The interactivity of electronic map allows user to work with different data visualizations and to search the data easily. Many examples of sensor data visualization can be mentioned. Herman, Reznik (2013) focused on interactive web cartographic presentation of data 
from noise sensors. Riquelme et al. (2009) used an interactive web application using Google Maps to present soil humidity and temperature measured by sensors.

It was mentioned above that map can be used in many fields, but it also means that maps are not used only by cartographers. A map must be not only legible but also understandable also for readers that are experts in their specialisation, however, not in cartography. The principles that are important for the clarity of thematic maps have been described for example by Medyńska-Gulij (2010). We can also cite Pickle (2003: 1): The designer's best efforts at data collection or analysis will be wasted by failure to communicate the results clearly. There are several ways to enable easy work with map to not experienced user. One of them is adaptive cartography (Reichenbacher 2004, Stanek et al. 2010, Meng 2005) allowing the customisation of map based on the context (situation) and the role of user.

This paper presents possibilities of using and implementation of adaptive cartography and visual seeking principles for interactive visualization and analysis of sensor based data measured in real time. Our solution is described on experimental application for precise farming that we developed during research project Agrisensor.

Our paper starts with theory about sensor data visualization (section Visualization of sensor data) and description of adaptive cartography principles (section Adaptive cartographic visualization). One example of using interactive web-based environment for visualization of data sensors for precise farming is introduced in section Client description. Section The application of adaptive visualization and visual seeking deeply describes how adaptive cartography principles were implemented in this project.

\section{Visualization of sensor data}

Effectiveness of any information system can be evaluated on the basis of its ability to deliver relevant, accurate, and timely information. Every sensor has a location, and a sensor location is almost always important. The spatial extension and near real time availability of sensor information layers in geospatial applications create a great potential. Various characteristics (e.g. meteoro- logical conditions) can be automatically read at frequent intervals and those readings can be aggregated with map layers from diverse sources into spatial data representation/visualization for diverse purposes.

Enhanced cartographic functionality is usually not spotlight of researchers of researchers focused on sensor data visualization (Richter 2009, Riquelme et al. 2009). Cartographic Web Services (CartoWS) proposed by Iosifescu, Hurni (2010) and further developed by Iosifescu (2011) pioneered the way for producing cartographically enhanced maps dynamically from geographic information. This extension of standardised Web Map Services (WMS) enabled not only extended cartographic functionality including the dynamic change of the colour, shape, size, and rotation of map symbols but also near real time interpolation of sensors measurements. The term "dynamic mapping" has potentially two meanings according to Lai, Yeh (2004):

- dynamism in terms of the currency of data presentation or real-time mapping,

- dynamism in terms of the vigour of symbolization brought about by motion and/or animation.

In the first instance, a map is renewed typically at set time intervals to convey the most up-to-date information to the readers. Some common applications involve traffic maps current up to the minute to communicate the present traffic conditions; weather maps to reveal subtle changes in temperature and barometer readings within the hour; and the continuous tracking of hurricanes as they sweep across the communities (real-time maps). In the second instance, much has been written e.g. Blok (2005), Turdukulov (2007) or Opach et al. (2011) - about the animation of maps to display spatio-temporal or non-temporal changes through a series of maps presented in quick succession (temporal and non-temporal maps).

The overall usability is often mentioned when speaking about the designing sensors visualization and interface. Plaisant (2004) emphasised the fitting of visualization to the wishes of the user and to the task as the main issue to be taken into account when preparing the visualization of sensors. In order to develop an effective visualization several authors (Andrienko, Andrienko 2006, Richter 2009) quoted Shneiderman (1996) and his Visual Information Seeking Mantra as a starting 
point to create a good visualization. Shneiderman (1996) enumerated seven tasks at a high level of abstraction when creating a design:

- overview - gain an overview of the entire collection;

- zoom - zoom in on items of interest;

- filter - filter out uninteresting items;

- details-on-demand - select an item or group and get details when needed;

- relate - view relationships among items;

- history - keep a history of actions to support undo, replay and progressive refinement;

- extract - allow extraction of sub-collections and of the query parameters.

Among the aforementioned principles, the four (overview, zoom, filter, and details on demand) can be considered as the "basic" and used for the development of any visualization interface.

\section{Adaptive cartographic visualization}

Currently - with the use of intelligent approach to databases and interactive user support - it is possible to find "ready to be used" maps on the Internet, but also to create and modify these maps according to specific and individual requirements. Instead of mere utilization of maps created by someone else beforehand, these new geoinformation technologies allow individuals to use cartography interactively, examine and represent spatial information according to specific needs of the particular user. Such a shift of map use from general public toward individuals is in general accordance with MacEachren (1995) and his changes in cartography.

Adaptation of geographic information can be seen as an optimization process that enables the provision of objects of high utility that satisfy a user's current situational context. Adaptation of GI can be carried out at data level, communications level, task-specific level, platform level etc. Geographic information adaptation methods have been proposed by different authors. The dominant model (paradigm) still concentrates on the aspects of data, although there has been recognition of the importance of the user's tasks (Erharuyi, Fairbairn 2005, Stanek et al. 2010).

Context can be also defined as the synthesis of conditions which can influence an adaptive map (Kozel et al. 2010). Each context is a combination of parameters describing user or his actual situation. In section In section The application of adaptive visualization and visual seeking, the process of adaptation is documented on example of agriculture, so the situation can be described with parameters crop (sugar beet, wheat etc.) and agricultural activity (sowing, harvesting etc.). A chosen combination of parameters changes information visualized in map.

Mishra, Punia (2007) simplified the division of domains according to the adaptable map components and quoted the specific features and techniques as follows:

- geoinformation adaptation - changing level of detail and degree of generalization, changing map file format, classification, information filtration,

- user interface adaptation - adapting by restricting the access level or simplifying the interface, web-like functionalities using different types of zooming, panning, rotating, selection, hotlinks,

- cartographic adaptation - orientation of map, change in map scale, change in colour scheme, change in symbolization style, change in position of user on map, focus on area of interest.

Despite relatively well developed conceptual basis described above, the practical examples or even fully fledged applications of adaptive systems are rather rare. Therefore we decided to apply selected principles of adaptive cartography on a pilot study in precision farming and combine them with visual seeking in order to develop an effective client for sensor measurement visualization.

\section{Client description}

This section deals with methods of acquiring, processing, and visualizing sensor observations for agricultural applications. It summarises the main results of the Agrisensor project ${ }^{1}$, which was focused on the development of a framework for accessing heterogeneous sensor data and services that support effective and near real time

1 Cartographic visualization of agricultural sensor based information - grant no. 205/09/1437 of the Czech Science Foundation. 


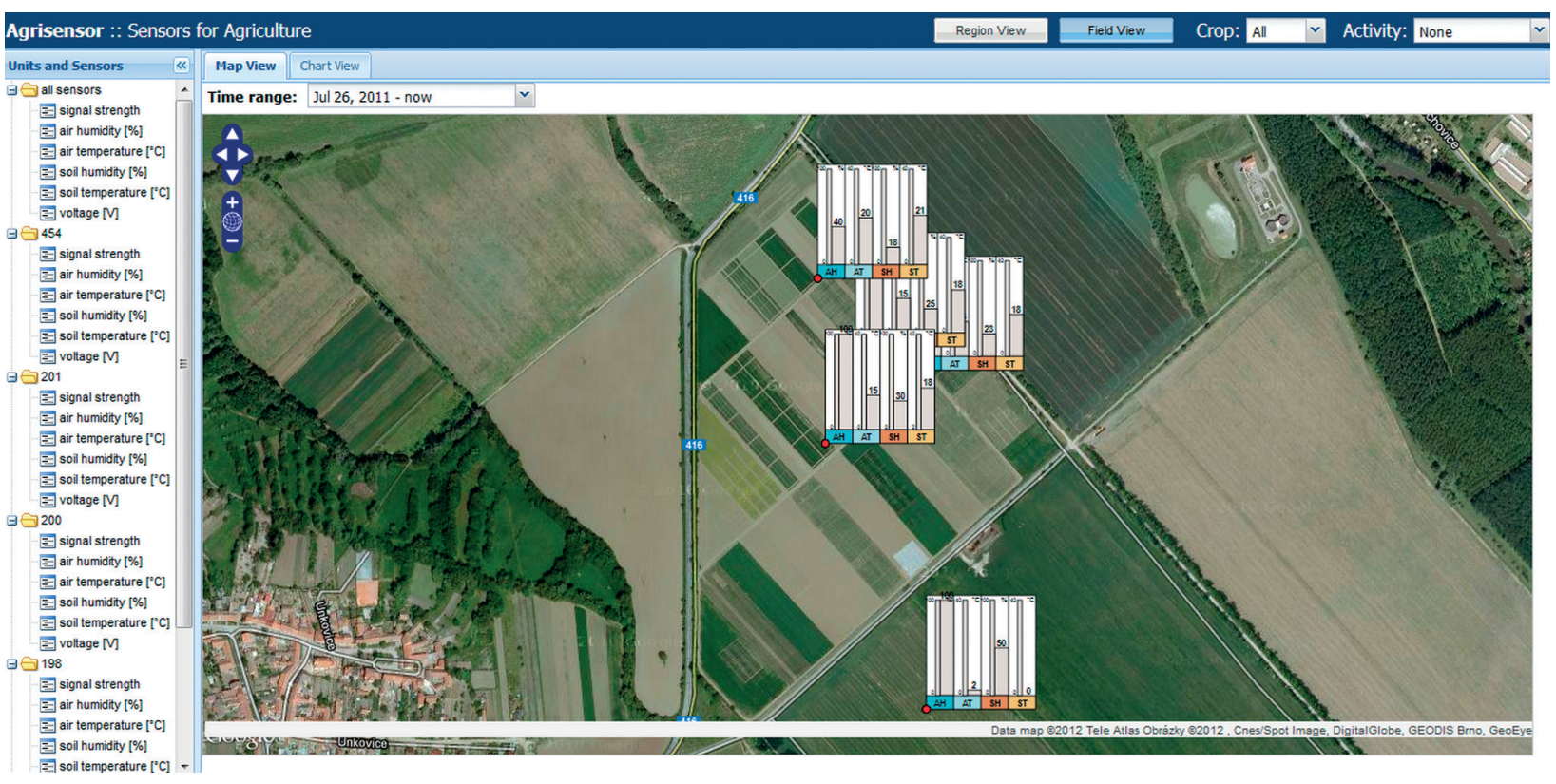

Fig. 1. Spatial visualization window showing experimental field with location of all sensor units.

decision-making in the area of agricultural management.

Sensor network used as near real time data source in Agrisensor project consist of sensor units. Each sensor unit measures several characteristics (temperature and humidity of both air and soil). Sensor units communicate with each other by RFID (Radio Frequency Identification) protocol. Furthermore, the measurement is sent to the relay station, which is a mobile communication unit based on GPRS (General Packet Radio Service) communication interface. Measured data are then sent automatically to the remote server and stored in database here. The database structure follows the Observations and Measurements (O\&M), which is an OGC (Open Geospatial Consortium) standard. Measured data are transmitted from the database to the client application in the JSON format (JavaScript Object Notation). This format can then be easily used for the AJAX (Asynchronous JavaScript and XML) client applications and interactive visualization in web environment. The details of the system architecture and the parameters of the individual components are described in Kubicek et al. (2013).

The sensor data must be appropriately visualized to allow their analysis and utilization. For visualization of measured sensor data, an interactive web client application was developed. It has been performed in accordance with the principles set out above during web client's devel- opment. Especially the concept of dynamic presentation (see section Visualization of sensor data) and adaptive visualization (see section Adaptive cartographic visualization) were followed. The client application allows dual view of sensor data, it consist from spatial (map view - Fig. 1) and temporal visualization (chart view - Fig. 2).

Spatial visualization was implemented using open source JavaScript library OpenLayers. The raster layers derived from WMS servers were used as a base layers for spatial visualization. The temporal visualization was implemented using the library HighCharts and displays the time series of sensor measurements in the form of line chart.

Spatial visualization, in the form of a map window, contains a set of predefined hierarchical levels of detail (from an overall view of the area of interest through the portrayal of individual experimental plots to the detail view of the immediate surroundings of the selected group of sensors). Individual sensors are symbolised by multivariate symbol with latest measured values appears. These multivariate symbols were implemented by SVG (Scalable Vector Graphics). After click on sensor symbol, there is possibility to switch to the time visualization. Details about implementation of adaptive cartography principles into spatial visualization are described in the sections Map view adaptation and Cartographic symbol adaptation. 


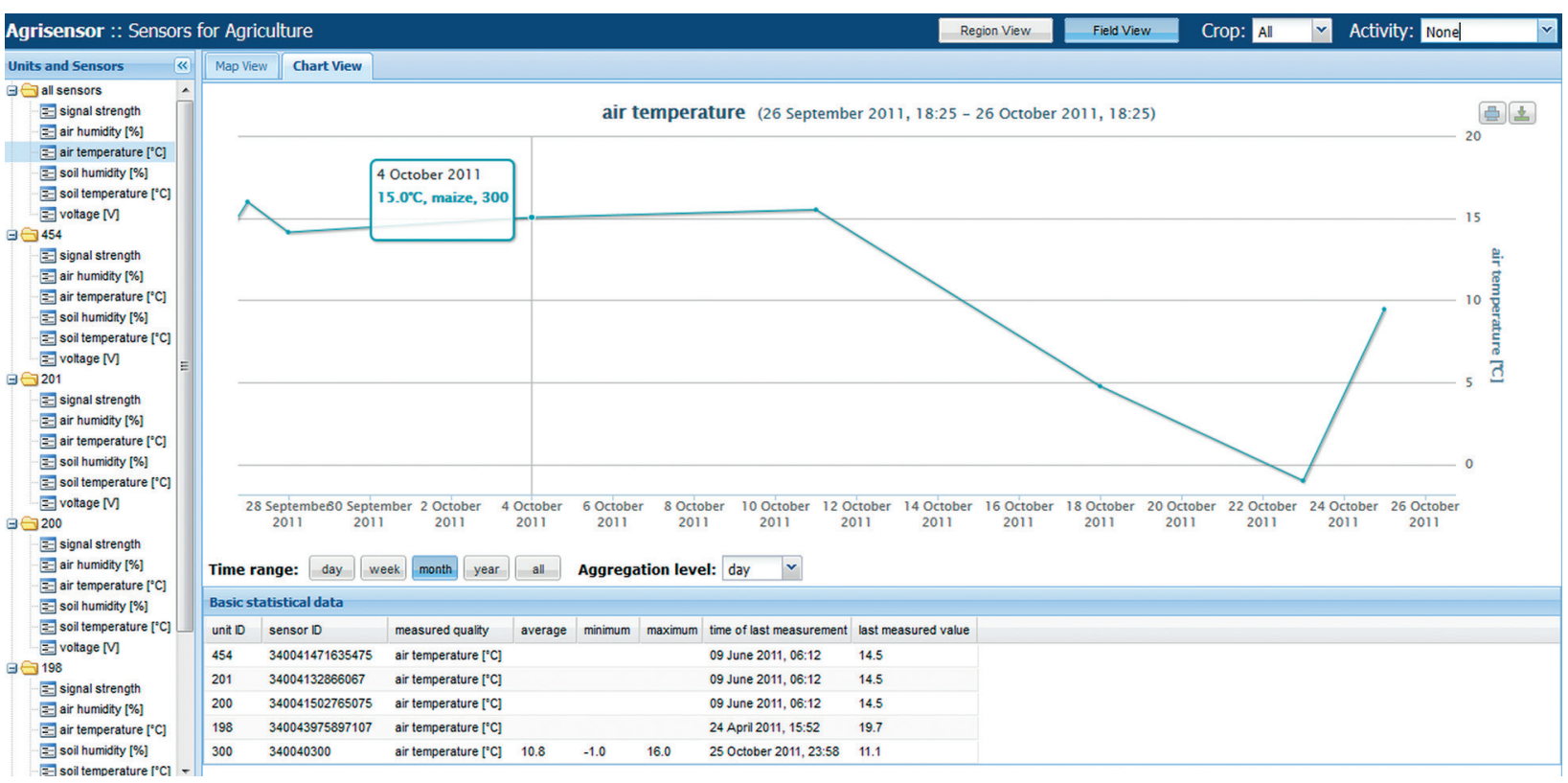

Fig. 2. Temporal visualization window presenting values from sensors that measure air temperature in time period 28th September - 26th October 2011. Aggregation level "month" is selected. Information about value in specific days (e.g. 4th October) is visualized after the movement of mouse over the chart.

In the temporal visualization, an interactive chart is drawn. Chart shows sensor and time range, which is selected by user. He may select one or more sensors measurement of the same phenomenon, so that the variations between different measurement points can be seen. Below the chart, user can study statistical information about currently displayed selection. The user can export and print the chart.

The zooming is also implemented in temporal visualization. User can use mouse cursor to select a part of time axis and zoom to more detailed time view (e.g. from months to days). It means that chart can be used for searching of measured values or their trend in whole period as well as for searching one exact value in exact time. Drawing of chart for whole year from values of single days would be time consuming. Therefore, the user has the option to choose level of aggregation - months, weeks, days or hours. In this case only mean values are transferred from source database (e.g. mean value for month instead of values for single days). Details can be found in Kozel et al. (2011). This solution allows fast time response of client on user demand and redrawing of line chart.

\section{The application of adaptive visualization and visual seeking}

Agricultural contexts are intended as a visual support for decision making in particular agro technical activities. In Agrisensor project each context is a combination of two parameters Crop and Activity. Parameter Crop sets on the spatial and temporal extent of available plots with relevant crop type (maize, barley, sugar beet, and wheat), while Activity parameter indicates the agro technical operation (sowing, harvesting, tillage, and fertilization). Particular context is then defined by Crop + Activity combination (maize + sowing) and by a set of appropriate agro meteorological parameters measured by sensors. The aforementioned principles of adaptive cartographic visualization (see section Adaptive cartographic visualization) were applied on three different levels - map view, dynamic cartographic symbol, and dynamic measurement chart. The implementation of Visual Information Seeking Mantra principles is described in section Implementation of visual seeking principles in client tools.

\section{Map view adaptation}

Crop is the driving parameter for map adaptation level. When choosing particular crop type 


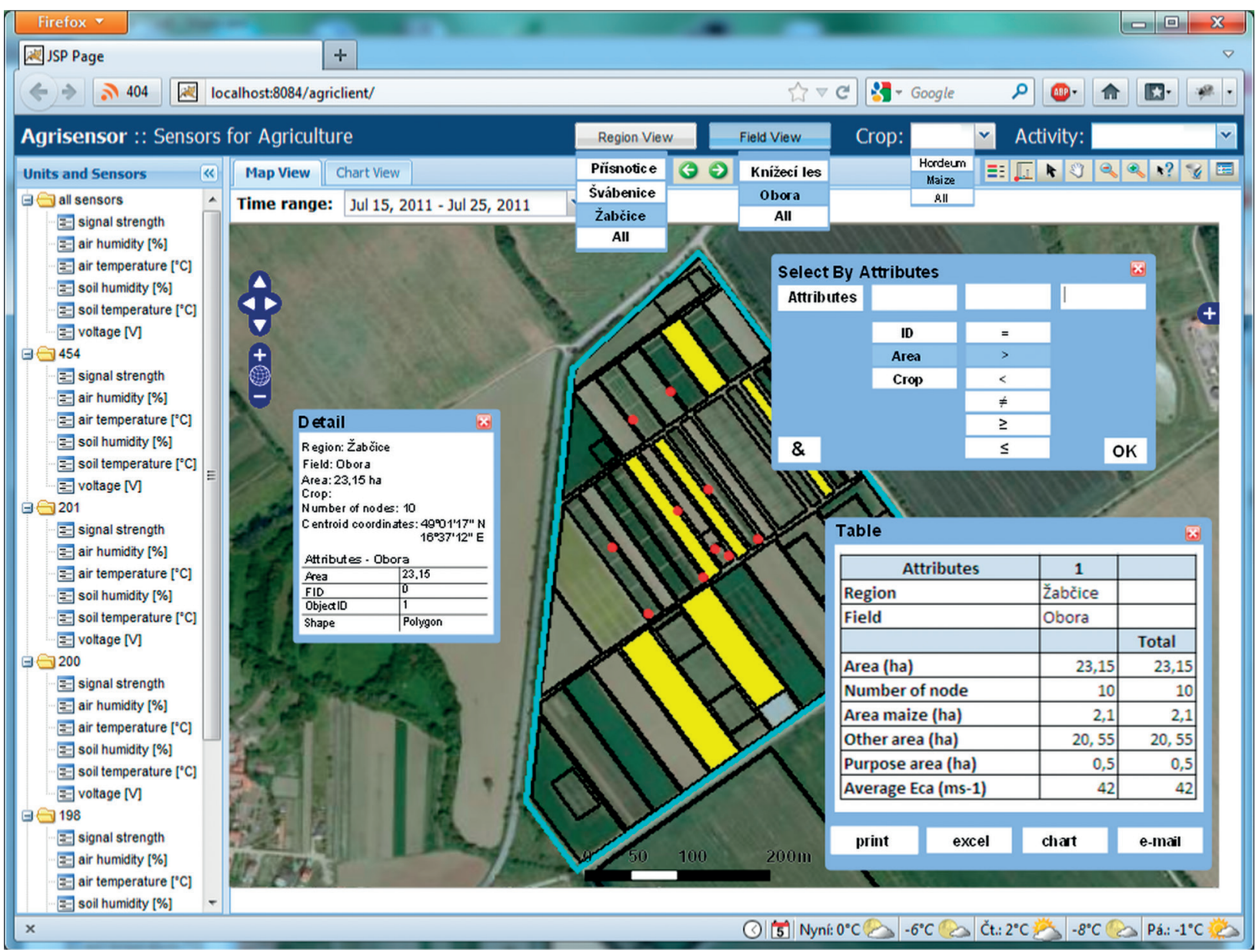

Fig. 3. Map visualizes only sensor units relevant for selected crop - “Maize" - in selected time range - "Jul 15-25" - on selected field - "Obora" - in selected village - "Zabcice". A selection of units can be done also by table or attributes. Source: Tynklova (2012).

and time span (crops are rotating for each season) the relevant field plots are highlighted. Highlighting is a specific type of cartographic adaptation (symbol change) proposed by Reichenbacher (2004). Visual enhancement of appropriate plots attracts users' attention (perception) only to plots with relevant crops. Also geoinformation adaptation is applied on the level of sensor measurements visualization. Choosing crop type and time span (season and year) activates the filtering function of sensors data and only sensors relevant for particular crop are visualized - see Fig. 3. Filtering is a location aware function in this time where the coordinates of particular sensor are compared with the area of crop within particular time span.

\section{Cartographic symbol adaptation}

Context parameters - crop and activity - have a specific function in case of symbol adaptation (special type of cartographic adaptation - see sec- tion Adaptive cartographic visualization). The crop determines if the symbol is shown or not and the activity specifies appearance of symbol. Multivariate symbol is proposed to portray the observations of air humidity, air temperature, soil humidity, and soil temperature simultaneously (Fig. 4). This base is modified by chosen context. Actual values of meteorological variables are compared with limits from given context. Limits are defined as a range of temperature or humidity, during which it is suitable to execute given agricultural activity.

From cartographical point of view sensor data maps are special type of thematic maps. The issue of thematic cartographic visualization is processed by different authors (e.g. Vozenilek, Kanok 2011, Slocum 2005). General principles for the creation of map symbols are also valid for the construction of symbols for sensor units. Pravda (2003) identifies three basic principles - conventional appearance, indifference and associativity 
(motivation). The biggest problem is complexity of symbols because they include four meteorological characteristics and also limits associated with a given context. Symbol should be as simple as possible, therefore it should be emphasized the information compression during the symbol design.

Another problem is the use of map symbols on the topographic base, which is orthophoto in this case. Therefore, it is appropriate to focus on the convex-shaped symbols and use colours that are sufficiently different from the base map (bright enough). The design of symbol, which has been used in client application, is based on a bar graph with a white background (see Fig. 4 - left part). The final appearance of the multivariate symbol is slightly different from the proposed form. The final form is shown in Fig. 4 on the right. Column widths are different, position and size of alphanumeric characters varies, too. Columns showing the limits, if they are not relevant for the given context, have been omitted because of the simplification of symbols. Design issue of multivariate symbols for agricultural activities describes in detail Tynklova (2012).

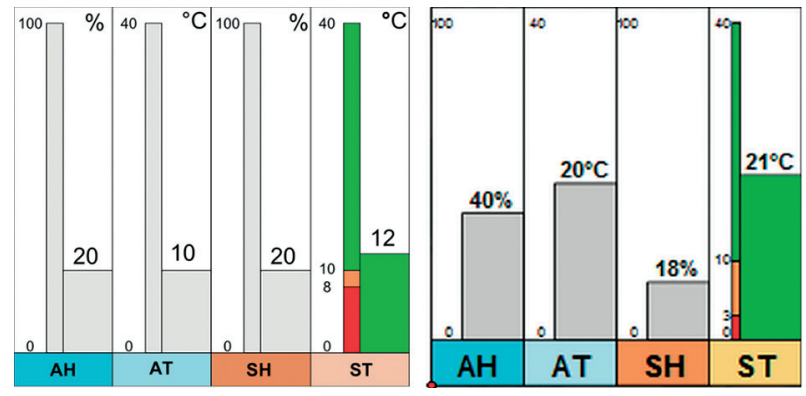

Fig. 4: Left: Propose of dynamically generated multivariate symbol for selected agricultural activity (in this case it is corn sowing). Right: The final form of the multivariate symbol (for context maize sowing). Air humidity (AH), air temperature (AT), soil humidity (SH), and soil temperature

(ST) represent here the observed characteristics.

According to comparison of actual values and context's limits the colour of some column is changing. When characteristic is in optimum, column have green colour. Very often only one meteorological variable is relevant for chosen context. Then this variable (e.g. soil temperature - ST - in Fig. 4) is the only one represented in colour, the other variables remaining grey. Right part of Fig. 4 and Fig. 5 show multivariate symbols for context maize sowing. Only soil temper-

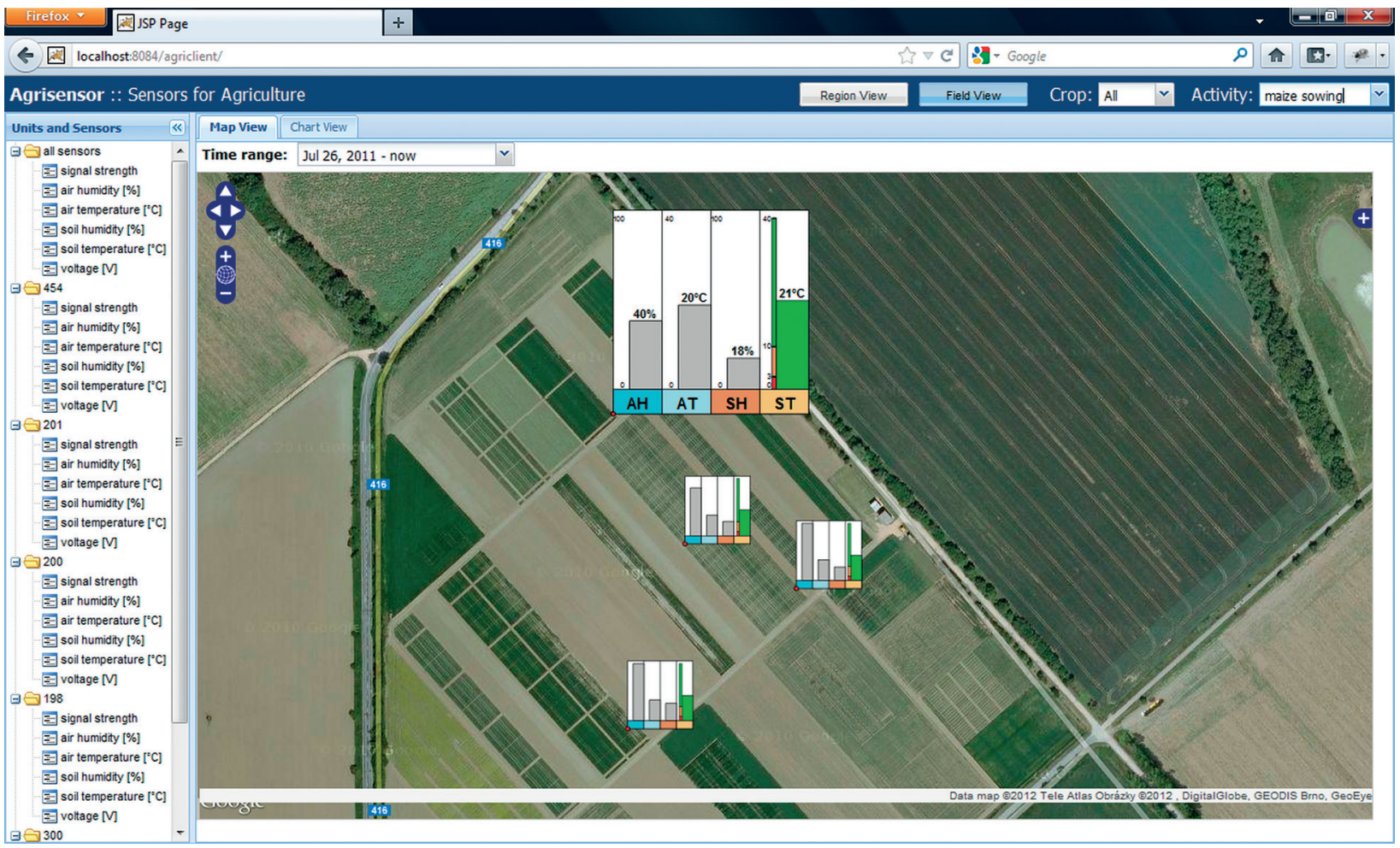

Fig. 5. Multivariate symbol shows air humidity (AH), air temperature (AT), soil humidity (SH) and soil temperature (ST) in specific place of sensor unit. Only soil temperature is important for selected context (maize sowing), so only this part of multivariate symbol is in colour. 
ature is the ruling climatic factor for this context. Limit values are also displayed in the character, here minimum is $3^{\circ} \mathrm{C}$ and optimum is $10^{\circ} \mathrm{C}$. Soil temperature of the current observation reaches within the green interval used for "optimum".

For implementation of described proposal were used SVG (Scalable Vector Graphic), JavaScript and DOM (Document Object Model). SVG symbols are drawn through SVG namespace and they are placed in vector layers from Open Layers library. Because of displaying all sensor units from study area, there were created two versions of symbol. Implicit symbol version was reduced to minimal size without numerical and textual parts. In case of mouse move over the symbol, it gets bigger, numbers and texts get visible - see in Fig. 5. Smaller symbol version is shown after mouse moving out. When clicking on symbol, you will see more information and links to graph section in a bubble. Using these techniques allows us to show both general overview (if the values are convenient for chosen context or not) and details on demand (actual values of observed characteristic).

\section{Measurement chart adaptation}

In the temporal visualization, an interactive chart is drawn based on specified sensor and time range. It is possible to choose one or more sensors measuring the same phenomenon. Basic visualization is modified by chosen context (e.g. wheat sowing in Fig. 6). Coloured part of chart (green belt) indicates values that are suitable for chosen agricultural context. This range corresponds to the optimum (green colour) in a multivariate symbol for same context. The same temperature or other meteorological variables can be indicated as suitable or unsuitable for different agricultural activities (contexts).

\section{Implementation of visual seeking principles in client tools}

Tasks of visual seeking proposed by Shneiderman (1996) and described in section Visualization of sensor data were implemented into the client. Visual seeking in the client application is realized through control tools, popup windows and linked windows of spatial and temporal visualizations. Implementation of each of tasks mentioned by Shneiderman (1996) is described below. Following tasks have been designed and partly implemented in the client (Fig. 7):

- overview - zooming out in map view show the localization of all fields with sensor units;

- zoom - user can then use zoom tool to see only one locality or only part of field or smaller group of sensor units;

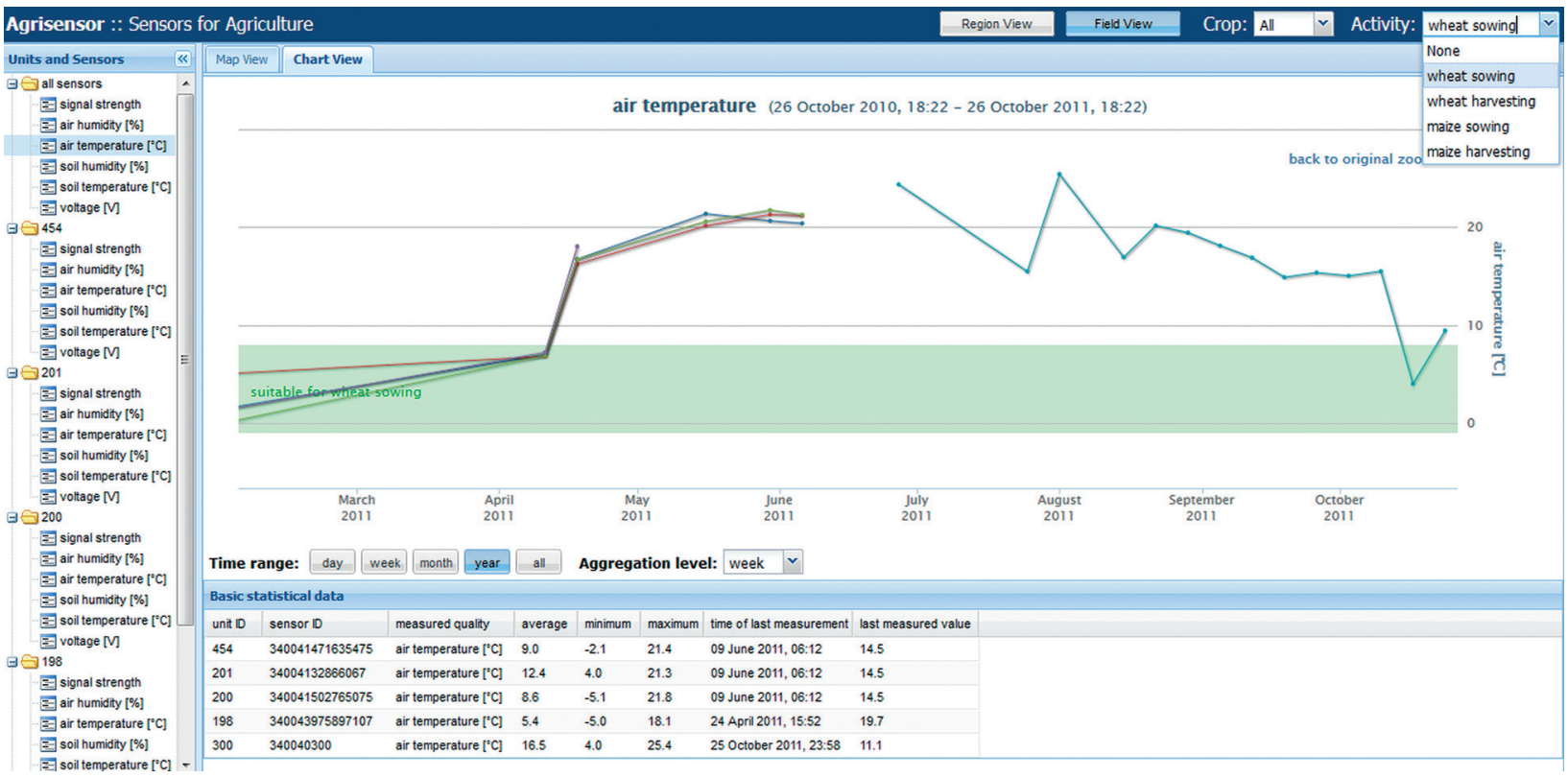

Fig. 6. Temporal visualization presenting values from all sensors that measured air temperature in the time period MarchOctober 2011. The range of values suitable for the selected context (wheat sowing) is indicated by a coloured background. 


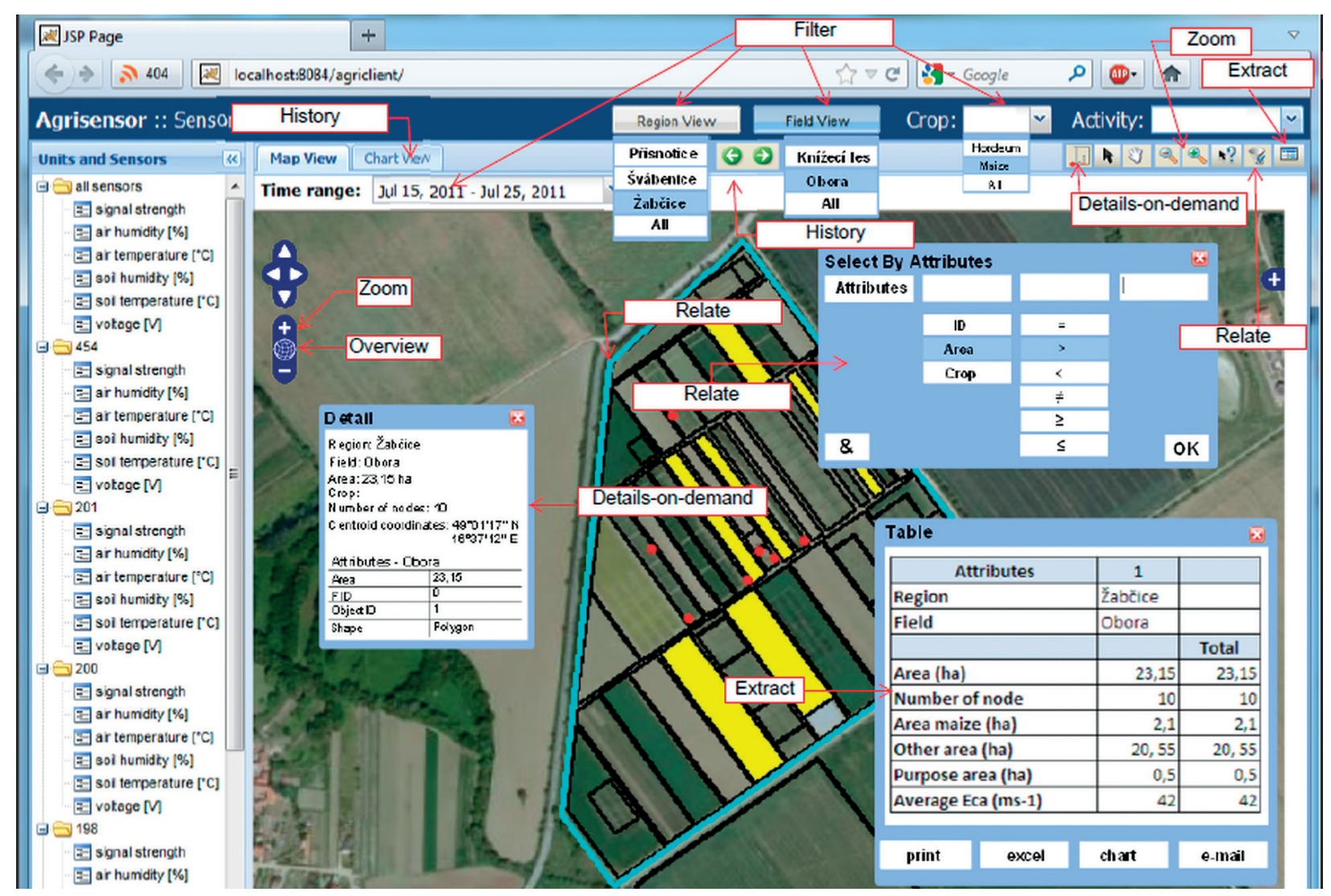

Fig. 7. Client window (the same context as in Fig. 3) with description of visual seeking tools. Adapted from: Tynklova (2012).

- filter - user can filter out sensor units that are not located in selected crop or selected time period;

- details-on-demand - user can click on symbol of sensor unit. A chart with history of measured values is shown. The maximum, minimum and average measured values are presented in a table including the last measuring time;

- relate - Relationships among items can be seen in comparing of localisation of sensor unit in map view and its measured values on chart view. Sensors units can be also found that are located in some specific crop or that have measured some exact values of temperature or humidity;

- history - history of measured values is visualized in chart view and history of zooming allow user to go back to last map extent without using zooming tool;

- extract - chart in the chart view shows values of selected sensors and table in the chart view shows general statistical parameters of measured values - mean, $\max$, $\mathrm{min}$, etc.
Linked views (spatial and temporal visualization) utilized in client application are specific example of linked plots concept. This connection allows user to switch between temporal and spatial visualization, and thus supports the detection of interdependencies or relations in the data. Concept of linked plots is also related with so called brushing. Brushing is according to Roberts, Wright (2006) collection of techniques to dynamically query, highlight and directly select elements on the visual display. User can brush in one view and see the results of that operation in other views. Full-featured application of the brushing would require simultaneous display of spatial and temporal visualization. Two simultaneous visualizations have not been used due to lack of space on the screen. It was preferred sufficiently large and clear display, among which user can switch between two types of views. Sufficient use of brushing also requires the use of appropriate colours (according to Andrienko et al. 2001). 


\section{Conlusion and future direction}

This paper presents theoretical possibilities of adaptive cartography for sensor data, explains how to connect them with visual seeking techniques, and exemplifies both on agro-meteorological data in web based interactive map application. The results of Agrisensor project proved that successful implementation of adaptive cartography and visual seeking is making work with application more effective and interesting for user. Easier and effective work with application can also cause that visualized data (e.g. sensor data but not only) can be used more efficiently.

Applied principles - namely geoinformation adaptation, cartographic adaptation, and partly interface adaptation - are just introductory examples of adaptive cartography in the field of both sensor visualization and agricultural context. Successful implementation and further use of adaptive principles will demand cooperation with other cartographic areas of specialization. In order to overcome the novelty of adaptive approach, an extensive use and usability study (van Elzakker et al. 2008, Griffin, Fabricant 2012, Ooms 2012) would be needed to confirm and refine the effectiveness and efficiency presented contexts. We are aware of this fact and plan further steps in this direction.

Another feature that would be very efficient for any future extended version of our client is the visualization of data uncertainty and quality. The data measured in real-time can be erroneous or unbelievable and it is useful to inform user about it. However, it is important to distinguish "non-valid" data and "variable quality" data.

Non-valid data are these without sense - e.g. humidity over $100^{\circ}$. These values should be handled on a database as an error; they should not be transferred and used for analysis in client. This was the way we used during the pilot implementation. On the other hand, variable quality data are caused by different reasons - sensor calibration, weather conditions (e.g. snow on sensor), incorrect position of sensor etc. The variable quality (or uncertainty) of such measurements could be marked in the client. Stachs et al. (2012) proposed the extension of the OGC Sensor Observation Service sending information about sensor data uncertainty (U-SOS) and also proposed a client depicting the probability distribution of a particular observation. Visualization of measured data uncertainty connected with principles of adaptation described above can potentially improve the visually supported decision making both in agriculture and in environmental sciences.

Presented agricultural contexts have a great application potential in real world scenarios. Since all measured agro-meteorological data are stored in the database, the cartographic symbols can not only visualize the current variables and their relevancy to a particular context but also the whole set of statistical variables of measured values (sum, max, min, median etc.). One example can be the effective temperature sum (ETS) used for the predictions of crop production and date of harvesting. The context and context based symbols can then be constructed as a combination of near real time measurements influencing the current activity in the field and statistical measure (sum) used for the prediction of harvest date.

\section{Acknowledgments}

Preparation of this paper has been supported by funding from the project of Masaryk University under the grant agreement No. MUNI/A/1370/2014, which is called Global Environmental Change of Component Earth's Spheres in Time and Space.

\section{References}

Andrienko N., Andrienko G., 2006. Exploratory Analysis of Spatial and Temporal Data. Springer Verlag, Berlin-Heidelberg.

Andrienko G., Andrienko N., Savinov A., 2001. Choropleth Maps: classification revisited. In: Proceedings of ICC 2001: 6-10 August 2001. Beijing. Edited by Scientific and Technical Program Committee LOC: 1209-1219. Online: http://geoanalytics.net/and/papers/ica01.pdf (accessed 20 May 2014).

Beroll H., Berke O., Wilson J., Barker I.K., 2007. Investigating the spatial risk distribution of West Nile virus disease in birds and humans in southern Ontario from 2002 to 2005. Population Health Metrics 5(3). DOI: 10.1186/1478-7954-53.

Blok C.A., 2005. Dynamic visualization variables in animation to support monitoring of spatial phenomena. Utrecht, Enschede, Universiteit Utrecht, ITC, 2005. ITC Dissertation 119, Nederlandse Geografische Studies $=$ Netherlands Geographical Studies 328. Online: http://www.itc.nl/ library/Papers_2005/phd/blok.pdf (accessed 30 April 2014). 
van Elzakker C.P.J.M., Delikostidis I., van Oosterom P. J.M., 2008. Field-Based Usability Evaluation Methodology for Mobile Geo-Applications. Cartographic Journal 45(2): 140-149. DOI: 10.1179/174327708X305139.

Erharuyi N., Fairbairn D., 2005. Task-centred adaptation of geographic information to support disaster management. In: van Oosterom P., Zlatanova S., Fendel E.M. (eds), Geo-Information for Disaster Management. Springer Verlag, Berlin-Heidelberg: 997-1008. DOI: 10.1007/2F3540-27468-5 70 .

Geryk E., Dite P., Kozel J., Kubicek P., Konecny M., Stampach R., Pesek M., 2010. Nádorové multiplicity u české populace (Cancer multiplicities in the Czech population). Casopis lekaru ceskych 4: 178-183.

Geryk E., Stampach R., Kozel J., Dite P., Konecny M., 2013. Výskyt dalších novotvarů u nemocných s leukemií (The incidence of other neoplasms in patients with leukemia). Onkologie 3: 135-139. Online: http://www.onkologiecs. cz/pdfs/xon/2013/03/08.pdf (accessed 5 May 2014).

Griffin A.L., Fabrikant S.I., 2012. More Maps, More Users, More Devices Means More Cartographic Challenges. Cartographic Journal 49(4): 298-301. DOI: 10.1179/000870 4112Z.00000000049.

Grönlund A., 2005. Methodology for making geographic information relevant to crisis management. In: van Oosterom P., Zlatanova S., Fendel E.M. (eds), Geo-information for disaster management. Springer Verlag, Berlin-Heidelberg: 121-128. DOI: 10.1007/2F3-540-27468-5_9.

Herman L., Reznik T., 2013. Web 3D Visualization of Noise Mapping for Extended INSPIRE Buildings Model. In: Hrebicek J., Schimak G., Kubasek M., Rizzoli A.E., Environmental Software Systems. Fostering Information Sharing. Springer Verlag, Berlin-Heidelberg: 414-424, IFIP Advances in Information and Communication Technology. DOI: 10.1007/978-3-642-41151-9_39.

Iosifescu I., 2011. Cartographic Web Services. Dissertation, ETH Zurich, Switzerland. Online: http:/ /e-collection.library. ethz.ch/eserv/eth:4541/eth-4541-02.pdf (accessed 30 April 2014).

Iosifescu I., Hurni L., 2010. GIS Platform for Interdisciplinary Environmental Research. In: Proceedings of the 7th ICA Mountain Cartography Workshop, 1-5 September 2010, Borsa, Romania. Online: http://www.mountaincartography.org/publications/papers/papers_borsa_10/09_ iosifescu.pdf (accessed 2 May 2014).

Kozel J., Stampach R., Zboril J., 2009. Adaptive map visualization: from context selection to web service configuration. In: Proceedings of $3^{\text {rd }}$ ISDE DIGITAL EARTH SUMMIT, Nessebar, Bulgaria.

Kozel J., Stampach R., Zboril J., 2011. Monitoring weather situation in the field: an approach based on Sensor observation service. In: Jalovecky R., Stefek A., Proceedings of the International Conference on Military Technologies 2011 (ICMT'11). University of Defence, Brno: 1315-1322.

Kubicek P., Kozel J., Stampach R., Lukas V., 2013. Prototyping the visualization of geographic and sensor data for agriculture. Computers and Electronics in Agriculture 97: 83-91. DOI: 10.1016/j.compag.2013.07.007.

Lai P.-Ch., Yeh A.G.-O., 2004. Assessing the Effectiveness of Dynamic Symbols in Cartographic Communication. The Cartographic Journal 41(3): 229-244. DOI: 10.1179/000870404X13300.

MacEachren A.M., 1995. How Maps Work: Representation, Visualization, and Design. Guilford Press, New York, USA.
MacEachren A.M., Kraak M.J., 2001. Research Challenges in Geovisualization. Cartography and Geographic Information Science 1: 3-12.

Medyńska-Gulij B., 2010. Map Compiling, Map Reading, and Cartographic Design in "Pragmatic Pyramid of Thematic Mapping". Quaestiones Geographicae 29(1): 57-63. DOI: 10.2478/v10117-010-0006-5.

Meng L., 2005. Egocentric Design of Map-Based Mobile Services. The Cartographic Journal 42(1): 5-13. DOI: 10.1179/000870405X57275.

Mishra K.K., Punia M., Mina H.L., 2007. Adaptive approach to mobile cartography. In: Vettore A., El-Sheimy N. (eds), The $5^{\text {th }}$ International Symposium on Mobile Mapping Technology, MMT ‘07 May 29-31, 2007, Padua, Italy. ISPRS Archives - Volume XXXVI-5/C55, 2007. Online: http:// www.isprs.org/proceedings/XXXVI/5-C55/papers/ mishra_kamal.pdf (accessed 30 April 2014).

Ooms K., 2012. Maps, how do users' see them. An in depth investigation of the map users'cognitive processes. Dissertation in Ghent University. Online: http://cartogis.ugent.be/ kooms/PhD/PhD_kooms.pdf (accessed 30 May 2014).

Opach T., Midtbø T., Nossum A., 2011. A New Concept of Multi-Scenario, Multi-Component Animated Maps for the Visualization of Spatio-Temporal Landscape Evolution. Miscellanea Geographica 1: 215-229. DOI: 10.2478/ v10288-012-0013-6.

Pickle L.W., 2003. Usability testing of map design. In: Braverman A., Hesterberg T., Minnotte M., Symanzik J., Said Y. (eds), Proceedings of the $35^{\text {th }}$ Symposium on the Interface. Salt Lake City, Utah: 42-56. Online: http:/ / www.interfacesymposia.org/I03/master.pdf (accessed 25 January 2014).

Plaisant C., 2004. The challenge of information visualization evaluation. In: Proceedings of the Working Conference on Advanced Visual Interfaces. ACM, New York, NY, USA: 109-116. Online: http://triton.cc.gatech.edu/hci-seminar/uploads/1/The \% 20Challenge $\% 20$ of $\% 20$ Information\%20Visualization\%20Evaluation.pdf (accessed 15 April 2014).

Pravda J., 2003. Mapový jazyk (Map language). Univerzita Komenskeho Bratislava, Prirodovedecka fakulta, Bratislava.

Reichenbacher T., 2004. Mobile Cartography - Adaptive Visualisation of Geographic Information on Mobile Devices. Disertation Thesis. Technische Universität München.

Richter R., 2009. Visualizing sensor data. Media Informatics Advanced Seminar on Information Visualization. Online: https://www.medien.ifi.lmu.de/lehre/ws0809/ hs/docs/richter.pdf (accessed 20 April 2014).

Riquelme L., Soto F., Suardiaz J., Sanchez P., Iborra A., Vera J.A., 2009. Wireless sensor networks for precision horticulture in Southern Spain. Computers and Electronics in Agriculture 68: 25-35. DOI: 10.1016/j.compag.2009.04.006.

Roberts J.C., Wright M.A.E., 2006. Towards Ubiquitous Brushing for Information Visualization. In: Proceedings of the Information Visualization, $10^{\text {th }}$ International Conference on Information Visualisation, 5-7 July 2006, London, UK. DOI: 10.1109/IV.2006.113.

Shneiderman B., 1996. The eyes have it: a task by data type taxonomy for information visualizations. In: Proceedings IEEE Symposium on Visual Languages: 336-343. Online: http://www.cs.ubc.ca/ tmm/courses/old533/readings/shneiderman96eyes.pdf (accessed 15 April 2014).

Slocum T., 2005. Thematic Cartography and Geographic Visualization. Pearson Education, Upper Saddle River. 
Stachs C., Jones R., Cornford D., Kiesow M., Williams M., Pebesma E., 2012. Representing Uncertainties in the Sensor Web. In: Proceedings of workshop Sensing a Changing World 2. Online: https://www.wageningenur.nl/en/ show/Sensing-a-Changing-World-2.htm (accessed 15 June 2015).

Stampach R., Geryk E., 2012. Health statistics in international databases and their cartographic visualization. Quaestiones Geographicae 31(1): 77-88. DOI: 10.2478/v10117012-0029-1.

Stampach R., Geryk E., 2011. Mezinárodní databáze zdravotních statistik a jejich dostupné údaje (International health statistics databases and available data). Casopis lekaru ceskych 7: 384-388.

Stanek K., Friedmannova L., Kubicek P., Konecny M., 2010. Selected issues of cartographic communication optimiza- tion for emergency centers. International Journal of Digital Earth 4: 316-339. DOI: 10.1080/17538947.2010.484511.

Turdukulov U.D., 2007. Visualizing the evolution of image features in time - series: supporting the exploration of sensor data. Enschede, ITC, 2007. ITC Dissertation 149. Online: http://www.itc.nl/library/papers_2007/phd/turdukulov.pdf (accessed 15 April 2014).

Tynklova K., 2012. Vybrané aspekty kartografické vizualizace dat senzoru (Selected aspects of sensor data geovisualization). Master thesis. Masaryk University, Faculty of Science, Brno. Online: http://is.muni.cz/th/212865/ prif_m/DP_Tynklova.pdf (accessed 15 March 2014).

Vozenilek V., Kanok J., 2011. Metody tematické kartografie: vizualizace prostorových jevu (Methods of thematic cartography: visualization of spatial phenomenon). Univerzita Palackeho v Olomouci, Olomouc. 